\title{
Unpacking the nexus: Different spatial scales for water, food and energy
}

\author{
David L. Bijl ${ }^{\mathrm{a}, *}$, Patrick W. Bogaart ${ }^{\mathrm{b}}$, Stefan C. Dekker ${ }^{\mathrm{a}}$, Detlef P. van Vuuren ${ }^{\mathrm{a}, \mathrm{c}}$ \\ a Copernicus Institute for Sustainable Development and Innovation, Utrecht University, Heidelberglaan 2, 3584 CS Utrecht, The Netherlands \\ ${ }^{\mathrm{b}}$ CBS Statistics Netherlands, PO Box 24500, 2490 HA Den Haag, The Netherlands \\ ${ }^{c}$ PBL Netherlands Environmental Assessment Agency, PO Box 30314, 2500 GH Den Haag, The Netherlands
}

\section{A R T I C L E I N F O}

\section{Keywords:}

Water-food-energy nexus

Spatial scales

Integrated assessment models

Virtual trade

International trade

Sustainability

Global models

\begin{abstract}
A B S T R A C T
Recent years have shown increased awareness that the use of the basic resources water, food, and energy are highly interconnected (referred to as a 'nexus'). Spatial scales are an important but complicating factor in nexus analyses, and should receive more attention - especially in the policy-oriented literature. In this paper, we 'unpack' the nexus concept, aiming to understand the differences between water, food and energy resources, especially in terms of spatial scales. We use physical indicators to show the differences in terms of absolute magnitude of production and the distance and volume of physical trade, for seven resource categories: water withdrawal, crops, animal products, bio-energy, coal, oil, and natural gas. We hypothesize that the differences in trade extent are related to physical characteristics of these resources: we expect high priced, high density, geographically concentrated resources to be traded more and over longer distances. We found that these factors, taken together, can explain some of the differences in trade extent (and thus spatial scale involved), although for each individual factor there are exceptions. We further explore the spatial scales by showing the bidirectional physical trade flows at the continental scale for crops, animal products, bio-energy and fossil fuels. We also visualize how nexus resources are directly dependent on each other, using a Sankey diagram. Since both direct dependencies and physical trade are present, we investigate the role of resource-saving imports, which is a form of virtual trade. The resource-saving imports highlight the importance of continental and global scales for nexus analyses.
\end{abstract}

\section{Introduction}

In examining the sustainability of natural resource use, the concept of the 'resource nexus' has emerged in recent years, expressing the idea that the production and consumption of resources such as food, water, energy and land are all intricately related (Bizikova et al., 2013; Finley and Seiber, 2014; Hellegers et al., 2008; Ringler et al., 2013, 2016; World Economic Forum, 2011a). For example, food production requires land and water, but also energy (to power machines and produce fertilizer). Energy production uses water in extraction and refinement of fossil fuels and for cooling thermo-electric power plants. Electricity production via hydropower reservoirs can be conceived of as both consuming water (due to additional evaporation) and conserving water. Fossil fuel extraction "consumes" land and water by polluting it. Land and water are also used in the production of bio-energy (both liquid biofuels and fuel wood or charcoal). Some food crops may be converted to biofuels - although separate crop varieties are often developed for food and for biofuels. Energy is necessary for desalination of water, but also for pumping groundwater, transportation to and from end users, and wastewater treatment. Finally, land itself is also intimately involved in the water cycle, by collecting precipitation and acting as buffer for water availability, and because irrigation rights are often tied to land ownership (Bos and Wolters, 1990). Note that these are only a subset of the possible interactions. Although natural ecosystems also require land and water, and support farming, forestry and water collection, we take an anthropocentric perspective and treat water, food and energy as commodities in this paper.

There is an awareness in research and policy communities that spatial scales are an important, but also complicating factor in any nexus analysis. Policy-related documents typically argue that management of the resource nexus should be organized at several policy levels simultaneously, each of which operates at a different spatial scale, such as local, watershed, national, and global scales (Bazilian et al., 2011; Biggs et al., 2015; World Economic Forum, 2011b). We get the impression that 'the' resource nexus is often seen as a monolithic thing, especially in policy communities, and that the role of spatial scales receives insufficient attention to date. To some extent, the role of spatial scales has been addressed in the scientific literature. For example,

\footnotetext{
* Corresponding author.

E-mail addresses: d.1.bijl@uu.nl (D.L. Bijl), patrick.bogaart@xs4all.nl (P.W. Bogaart), s.c.dekker@uu.nl (S.C. Dekker), detlef.vanvuuren@pbl.nl (D.P. van Vuuren).
} 
Table 1

Main data sources used in this study.

\begin{tabular}{|c|c|c|}
\hline Dataset & Reference & Description \\
\hline Comtrade & Comtrade (2016) & Bidirectional imports between countries (in kg and US\$) for detailed commodities (SITCv1), for 1962-2015. \\
\hline CEPII & Mayer and Zignago (2011) & Distances between and within countries (in km) based on locations and population sizes of major cities, for 2004. \\
\hline FAOFBS & FAOSTAT (2014) & Food Balance Sheets per country and commodity, for 1961-2011. \\
\hline FAOLAND & FAOSTAT (2016) & Land area per end use and country (the Land Inputs database), for 1961-2013. \\
\hline FAOPOP & FAOSTAT (2016) & Population per country, for $1950-2100$. \\
\hline FAOPROD & FAOSTAT (2016) & Production (in kg) for detailed commodities per country (the PRODSTAT database), for 1961-2013. \\
\hline IEAHED & IEA (2016a) & $\begin{array}{l}\text { Headline Energy Data. Import and production of energy commodities (in J), for large energy producing or } \\
\text { consuming countries and some regional aggregates, for 1971-2015. }\end{array}$ \\
\hline IMAGE & $\begin{array}{l}\text { Bijl et al. (2016); Bondeau et al. (2007); } \\
\text { Stehfest et al. (2014) }\end{array}$ & Water withdrawal (model output) and population size per IMAGE region, for 1971-2100. \\
\hline
\end{tabular}

Garcia and You (2016) explain that each of the links between water, food, energy and land occurs at a particular spatial scale, while in Hejazi et al. (2015) the importance of interdependencies between nexus resources varies with the spatial scale. We take a different approach and 'unpack' the nexus concept by starting with the differences between the resources themselves, especially in terms of spatial scales.

In this paper, we explore the role of spatial scales in the water-foodenergy (WFE) nexus. We first show how water, food and energy are very different resources in terms of overall magnitude of flows and the extent of trade. Each resource involves different spatial scales, since the distance and volume of physical trade differs per resource. We then hypothesize that the extent of trade is related to the physical characteristics of the resources. We expect more trade over longer distances for resources with (1) a high price since transportation costs are then relatively small, (2) a high density since these should be easier to transport, and (3) little geographic overlap between supply and demand locations (i.e. the resource is hard to source locally). Next, we visualize physical transportation of nexus resources between continents, to further specify the average trade distances mentioned previously, to highlight the bi-directionality of trade flows, and to show that 'long distance' does not necessarily equate to 'global'. This also shows that the continental scale is important as an intermediate scale of analysis between the national and global scale, since continents have different climates and natural resource endowments, and most continents are separated by oceans which restrict the modes of transport. Besides physical trade, resource-saving imports (virtual trade) are another important mechanism through which nexus resource uses at local and national scales are tied together over long distances (i.e. involving continental- or global-scale systems) (Chapagain et al., 2006; Hoekstra and Hung, 2002). When the production of resource A (e.g. crops) is directly dependent on resource B (e.g. water), and resource A is traded physically, then resource B is said to be traded virtually via resource A (e.g. virtual water trade). We therefore also show how the production of some of the nexus resources is directly dependent on other nexus resources, using a Sankey diagram at the global scale. Besides the wellknown resource-saving concept of water saved by importing crops, we also estimate the volume of water saved by importing animal products, the water saved by saving feed crops by importing animal products, and the land area saved via the same mechanisms. Finally, the understanding of scale dependencies of nexus resources is not only interesting for the current situation, but also for the future. Our integrated quantitative approach may serve as a starting point for analysing how the relevant spatial scales for particular resources may change in the future due to socio-economic trends, climate change impacts and climate change mitigation.

The paper is organised as follows. After explaining our data sources and calculations (Section 2), we examine the differences between water, food and energy resources, especially in terms of spatial scales, by comparing physical characteristics (Section 3.1). Next, we show production and trade flows of the nexus resources at the continental scale (Section 3.2). In Section 3.3, we visually display and further investigate the direct dependencies between the resources, now also including land as an input. Section 3.4 combines direct dependencies and physical trade to estimate resource-saving imports and discuss the implications for spatial scales. In Section 4 we provide suggestions for further research, and the main findings are summarized in Section 5. The Supplementary information contains equations, additional physical indicators, a discussion of potential future changes and an overview of the relevant spatial scales for each resource.

\section{Methods}

Our approach is to analyse the spatial scales involved in the resource nexus in its current state, using openly available databases as much as possible, and filling the gaps with output from existing model simulations. We present the data requirements and calculations for the physical characteristics (2.1), the direct dependencies between resources (2.2), resource-saving imports (2.3) and the continental scale analysis (2.4). The main data sources with references are listed in Table 1.

\subsection{Physical characteristics}

We calculate the physical characteristics of the nexus resources for the following three reasons: (1) to explore the differences and similarities between the resources, (2) to explore how the differences relate to spatial scales (using trade distance and volume), and (3) to explore potential explanatory factors for the extent of trade. Regarding the third point, we expect more trade over longer distances for resources with a high price (since transportation costs are then relatively small), high density (since these should be easier to transport), and little geographic overlap between supply and demand locations (i.e. the resource is hard to source locally).

For water, we only focus on withdrawal, for food we distinguish crops and animal products and for energy we distinguish bio-energy, coal, oil and gas. We hereby have seven different nexus resources in total. The flow size of these seven resources is estimated by (i) the global total production. The trade extent is represented by (ii) the percentage of production traded internationally and (iii) the average trade distance. To explain the trade extent in terms of characteristics of the resources themselves, we calculated the (iv) average price of imports, (v) the densities of the resources and the (vi) geographic concentration of supply/demand. Note that bidirectional trade data are needed, since net trade data may obscure the actual physical transportation. The physical characteristics are calculated as follows (see the equations in the Supplementary information).

Total production of the seven resources is calculated in terms of mass (Gt) and energy (EJ). For water, we define "production" to be withdrawal, which is the amount abstracted from freshwater sources, based on the integrated assessment model IMAGE (Bijl et al., 2016; Bondeau et al., 2007; Stehfest et al., 2014). Production of food commodities in mass is aggregated from FAO Food Balance Sheets 
(FAOFBS) (FAOSTAT, 2014). Their energy content is estimated from the ratio of kcal/cap/day and g/cap/day for the Food Supply component in FAOFBS. Production of energy commodities in energy terms is aggregated from the International Energy Agency Headline Energy Data (IEAHED) (IEA, 2016a). These are subsequently converted to mass terms using the specific energy (EJ/Gt) estimated as the median of 2004-2014 ratios of global imports in EJ from IEAHED and imports in Gt from Comtrade (Comtrade, 2016).

(i) The percentage international trade of crops and animal products is calculated by dividing the total bidirectional imports from Comtrade by global production from FAOFBS (both in mass terms). Although Comtrade and FAOFBS use different categorization systems, we have created aggregate categories that match as much as possible. For energy commodities, both import and production (in energy terms) come from IEAHED.

(ii) The total trade distance is the domestic trade distance plus the product of the percentage traded internationally and the international trade distance. As a proxy for the domestic distance we use the mean distance between major cities in a country from CEPII (Mayer and Zignago, 2011), then aggregate weighted by production per country (FAOFBS for food, IEAHED for energy). The average international trade distances for food and energy commodities are based on bidirectional imports (in mass terms) from Comtrade and country-to-country distances from CEPII.

(iii) The average price of imports (in US\$ $/ \mathrm{kg}$ ) is the ratio of global imported value (US\$) and imported mass $(\mathrm{kg}$ ), both from Comtrade. Although the ratio of reported value and mass differs substantially for each importer-exporter link and year, the global aggregate is a robust indicator. To facilitate comparison between different years, we adjusted for inflation using the USA GDP deflator to 2009 prices (BEA, 2016). The average price is converted to $\$ / \mathrm{GJ}$ and $\$ / \mathrm{m}^{3}$ using estimates of bulk transport density ( $\mathrm{kg} /$ $\mathrm{m}^{3}$ ) described below, and specific energy ( $\mathrm{MJ} / \mathrm{kg}$ ) listed in the Supplementary information. The volume of bulk water imports across country borders (via pipes, canals or giant water bags) is insignificant at a global level. Transboundary flows via natural rivers are significant in volume, but are not included here because these flows are not intentional - they do not result directly from human decisions. For the price of water, we present estimated desalination costs as a proxy, at $0.001 \$ / \mathrm{kg}$ (Zhou and Tol, 2005).

(iv) The density of bulk transports $\left(\mathrm{kg} / \mathrm{m}^{3}\right)$ for water is simply the density at $0-20{ }^{\circ} \mathrm{C}\left(1000 \mathrm{~kg} / \mathrm{m}^{3}\right)$. For the six food and energy resources, the density is an average of typical densities for 25 food and 4 energy commodities listed in Supplementary information Table S2 (Hapman, 2016; SImetric, 2016; USDA, 2016; USDoE, 2013), weighted by trade mass from Comtrade.

(v) Concentration of supply: We expect that a resource is traded over longer distances if there is little geographic overlap between demand and supply. The Gini coefficient of production per capita serves as a proxy for this, since a high coefficient implies there are some countries with abundant resources and few people while other countries have few resources and many people. Production per capita is calculated at the country level for food commodities, based on FAO databases FAOPROD and FAOPOP (FAOSTAT, 2016). However, due to lack of data, production per capita is calculated at the level of larger regions for energy commodities, based on IEAHED and FAOPOP, and for water, based on IMAGE. This means the inequality is slightly underestimated for water and energy (i.e. the geographic distribution is more unequal than these numbers indicate).

Although price (e.g. in $\$ / \mathrm{m}^{3}$ ) may be correlated with density ( $\mathrm{kg}$ / $\mathrm{m}^{3}$ ) and local scarcity, we include it as a separate factor because the average price also reflects the number and value of potential uses inherent to the resource. Additional data and intermediate calculations are listed in Supplementary information Table S1.

\subsection{Continental scale production and trade}

To investigate the globally linked resource nexus at the continental scales, we calculate production and bidirectional trade for eight continents: North America, Latin America, Europe, Africa, the Middle East, Russia and Eastern Europe, Asia, and Oceania. We have reduced the continental scale analysis to four categories: crops, animal products, bio-energy and fossil fuels, by aggregating all fossil fuels and noting that bulk water trade is negligible.

For animal products and crops, continental production is aggregated from FAO and bidirectional trade between continents from Comtrade. For bio-energy and fossil fuels, continental production is aggregated from IEAHED and bidirectional trade between continents is the total energy import for each country (IEAHED) multiplied with the relative fractions of Comtrade flows from each source country to the respective importer, then aggregated to continents.

\subsection{Direct dependencies}

When one resource is used in the production or transformation of another resource, the latter resource is directly dependent on the first resource. To analyse the direct dependencies between the resources, additional data is required to distinguish the various water uses, food (crop) uses, and energy uses. Animal products such as meat and milk are not used in the production of other nexus resources and are therefore not differentiated per use. Since land is a major input for the production of food and bio-energy, the WFE nexus is now expanded to include land.

Water withdrawal for irrigation is based on output of the agro-hydrological model LPJmL (Bondeau et al., 2007) and on Bijl et al. (2016) for the electricity, industry and municipal sectors. Water withdrawal for fossil fuel extraction and refining is estimated from fuel-specific intensities (Schornagel et al., 2012) and production (IEAHED). The result is then subtracted from overall industrial water use as estimated by Bijl et al. (2016). Fuel wood is assumed not to be irrigated. Irrigation water for liquid biofuels is estimated from biofuel land use, crop land use, and irrigation volume per IMAGE region (from LPJmL), then summed to the global total. In IMAGE, biofuel crops are assumed not to be irrigated, but here we assume that in each region, biofuels are irrigated to the same extent as crops for food and feed.

Food crop uses are calculated directly from FAOFBS. These flows are larger than the flows based on FAOPROD, since these are in terms of primary product equivalent and include some additional minor categories. Crops used for biofuels are based on the IMAGE model (Stehfest et al., 2014) and then subtracted from Industrial/other use (FAO category "Other Utilization").

Primary energy use for electricity, agriculture, industry, municipalities, transport and feedstock is based on IMAGE model results, as are the various uses of electricity. Energy use for fossil fuel extraction and fuel wood harvesting and processing are estimated using a global average EROI (Energy Return On energy Invested) of 46:1 for coal and 20:1 for oil and gas (Hall et al., 2014), and 25:1 (Pandur et al., 2015) and 15:1 (Bailis et al., 2013) for modern and traditional uses of fuel wood, respectively. The resulting uses of energy for fossil fuels and for fuel wood are subtracted from the modelled industrial energy use. Energy use for water (e.g. pumping, treatment, etc.) is based on the World Energy Outlook 2016 (IEA, 2016b) and then subtracted from municipal energy use.

Land uses are aggregated from the FAOLAND database (FAOSTAT, 2016), except for land use for liquid biofuels such as biodiesel and ethanol, which is based on IMAGE model output. Liquid biofuels make up only a small portion of the overall category "bio-energy", in which the rest is fuel wood - whether harvested in a traditional or modern way. As a rough estimate of the forest surface area from which fuel 
wood is harvested, we take the FAO categories "Planted forest" and "Other naturally regenerated forest". This latter category indicates forest land with clearly visible indications of human activities, including selective logging, abandoned agricultural land, human-induced fires, and areas with a mix of planted and naturally regenerated forest or where it is not possible to distinguish between planted and natural regeneration. Together, these two categories should roughly equate to the actual forest area used for fuel wood. Wood harvested for non-fuel purposes, such as paper/pulp, construction, or furniture, is included in this rough estimate, since (1) the volume of wood used for fuel is much larger than for these other uses, and (2) a significant part of the non-fuel wood is still used as fuel at the end of its life cycle, for instance in wastepowered electricity generation.

\subsection{Indirect use and resource-saving imports}

In addition to direct relationships between the resources, there are also indirect uses, i.e. when resource $\mathrm{A}$ is an input to resource $\mathrm{B}$, which in turn is an input to C. This also raises the issue of virtual trade. A resource is traded virtually when it is used as an input in the production of a second resource, which is then widely traded. For example, virtual water trade via crops is water used for the production of crops which are traded internationally (Hoekstra and Hung, 2002). A concept related to virtual trade is that of "resource-saving imports" (Chapagain et al., 2006), which in this example represents the volume of water that would be needed if the importing country had produced all their crops domestically. We examine the possibility of resource-saving imports because it influences the nexus situation at smaller spatial scales via trade of other resources at larger spatial scales.

We estimate the water volume and land area saved by importing crops and animal products (see the equations in the Supplementary information). Demand, production, and net import of crops and animal products are calculated in terms of dry matter. The intensities are specified for each importing region, but we only have a global average available for water use per Mt of animal products. For a consistent comparison between domestic resource use and resources saved by imports, all variables (except water for animals) are based on IMAGE (Stehfest et al., 2014), LPJmL (Bondeau et al., 2007) and demand models for food and water (Bijl et al., 2017a,2017b, 2016, under review.). Since the import of animal products also saves feed crops that would otherwise have to be grown domestically, we separately calculate the land and water saved indirectly by animal imports via crops.

\section{Results}

\subsection{Key physical characteristics of water, food and energy}

We investigate the scale dependencies of the seven resources by calculating the total production magnitude, and then focus on the spatial scales involved in physical trade by examining trade distances and the importance of trade relative to production (Table 2). The broader resource categories of water, food and energy are represented here by seven sub-categories: water withdrawal, crops, animal products, bio-energy, coal, oil and gas.

\section{Size of total flows}

The first key difference in Table 2 is the different size of each resource production flow. In terms of mass, water use is three orders of magnitude lager than the flows of the other two resources, which are more comparable in size. Total energy flows are about 1.6 times as large as total food flows in terms of mass. In terms of energy content, the energy flows are considerably larger than food flows: a factor 9. These differences in magnitude can have implications if production flows get coupled. For instance, in the case of bio-energy relatively small flows in terms of the energy system could already be large compared to the biomass involved in the entire food system.
Trade volumes and distances

Table 2 shows that water and bio-energy markets (dominated by fuel wood) mostly occur at the sub-national scales. Of both animal and crop production $7 \%$ is traded internationally, whereas this percentage is much higher for energy commodities: $21 \%$ for coal, $29 \%$ for natural gas and $51 \%$ for oil. The total average trade distances follow a similar pattern (Table 2), with the longest distance for oil, then coal, natural gas, crops, animal products, and bio-energy. The order is the same as for percentage traded, except we found a shorter distance for natural gas. Most natural gas is carried by pipeline over land, while trade over longer distances by ship is often still more expensive, since it requires liquefaction to increase the density.

\section{Potential explanatory factors for the extent of trade}

The wide range in the trade percentages and distances arises from many contributing factors, some of which are attributes of the resource itself. First, one would expect low priced resources to be traded less than higher priced resources, since transportation costs would be a relatively larger obstacle to transporting low priced resources. This hypothesis seems to be confirmed for water (low price, little trade) and the energy commodities (high price, much trade). However, crops and animal products are traded less but have much higher average prices than energy commodities (in $\$ / \mathrm{kg}, \$ / \mathrm{GJ}$ and $\$ / \mathrm{m}^{3}$ in Table 2). A second factor is the difference in density $(\mathrm{kg} / \mathrm{l})$, since high-density resources should be easier to transport over long distances. This relation holds for the food and energy commodities: Oil has the highest density $(0.88 \mathrm{~kg} / \mathrm{l})$ and is transported the furthest, followed by coal, crops and animals, natural gas, and bio-energy - but water is the exception (with the highest density and almost no trade). Thirdly, regardless of price or density, we expect more trade when demand and supply are geographically concentrated in different areas. The mismatch between demand locations and supply locations is indicated by the differences in production per capita between countries, expressed as a single Gini coefficient for each resource. A high coefficient implies that most of the production occurs in countries with little population, thus necessitating exports to the other countries with high population and little domestic production. This Gini coefficient matches the extent of trade fairly well (both as\% and in $\mathrm{km}$ ), since it is highest for oil (0.71) and gas (0.67), followed by coal (0.40) and animal products (0.39), crops and water (both 0.29 ), and is lowest for bio-energy (0.24). Thus, for water and bio-energy (mostly fuel wood), a key reason for its limited trade (besides the relatively low price) is the relatively equal distribution of supply across different areas of the world. In summary, the price, density and geographic distribution of resources, taken together, can explain some of the differences in the trade distance and percentage traded. However, many other factors were not examined and may also play a role, such as import quota and tariffs, export subsidies, cultural similarity, and historical relations (e.g. former colonies), among others.

\subsection{Continental scale production and trade}

The differences in terms of production and trade around the world can be made more specific by looking at the continental level. Each continent is different in terms of climatic circumstances, natural endowments and a historically developed structure of the economy. Fig. 1 shows the global production and trade patterns for four resource categories: animal products, crops, bio-energy and fossil energy.

Asia is actually the largest producer for each resource category, indicated by the area size of the circle, partly in response to high overall demand (the region has the largest population). In Fig. 1A, animal products are traded in both directions between many continents. The largest importer is Asia, with only small amounts of export. Africa does not export significant amounts of animal products to other continents, while South America imports from North America and exports to five different continents.

Fig. 1B shows that food crops are traded in two directions between 
Table 2

Key physical characteristics for production and consumption of seven nexus resources.

\begin{tabular}{|c|c|c|c|c|c|c|c|c|}
\hline \multirow[t]{2}{*}{ Indicator } & \multirow[t]{2}{*}{ Unit } & \multirow{2}{*}{$\begin{array}{l}\text { Water } \\
\text { Withdrawal (2011) }\end{array}$} & \multicolumn{2}{|l|}{ Food } & \multicolumn{4}{|l|}{ Energy } \\
\hline & & & Crops (2011) & Animal products (2011) & Bio-energy ${ }^{a}(2014)$ & Coal (2014) & Oil (2014) & Gas (2014) \\
\hline \multicolumn{9}{|l|}{ Flow size } \\
\hline \multirow[t]{2}{*}{ Global production } & $\mathrm{Gt}$ & 3691 & 8.1 & 1.3 & 3.3 & 5.9 & 3.8 & 2.1 \\
\hline & EJ & - & 56 & 6 & 81 & 166 & 180 & 123 \\
\hline \multicolumn{9}{|l|}{ Trade extent } \\
\hline Intl. trade as $\%$ of global production & $\%$ & $\sim 0 \%$ & $7 \%$ & $7 \%$ & $1 \%$ & $21 \%$ & $51 \%$ & $29 \%$ \\
\hline Total avg. trade distance & $\mathrm{km}$ & small & 1196 & 1168 & 283 & 2079 & 3561 & 1505 \\
\hline \multicolumn{9}{|l|}{ Explanatory factors } \\
\hline \multirow[t]{3}{*}{ Avg. price of imports } & $\$ / \mathrm{kg}$ & 0.001 & 0.78 & 3.21 & 0.12 & 0.09 & 0.69 & 0.55 \\
\hline & $\$ / G J$ & - & 112.1 & 694.6 & 5.0 & 3.1 & 14.5 & 9.7 \\
\hline & $\$ / \mathrm{m}^{3}$ & 1 & 523 & 2139 & 43 & 72 & 609 & 252 \\
\hline Density & $\mathrm{kg} / \mathrm{l}$ & 1.00 & 0.67 & 0.67 & 0.34 & 0.83 & 0.88 & 0.46 \\
\hline Concentration of supply/demand & Gini & 0.29 & 0.29 & 0.39 & 0.24 & 0.40 & 0.71 & 0.67 \\
\hline
\end{tabular}

${ }^{\text {a }}$ Bio-energy combines both traditional and modern bio-energy resources. It consists mostly of fuel wood, but includes charcoal and liquid biofuels.

North and South America, between Europe and Africa, and between Europe and Russia/Eastern Europe. The bi-directional North-South trade is partly caused by the opposite growing seasons. North America is the largest net exporter and Asia the largest importer. Again, South America exports to various continents, in this case four.

Fig. 1C shows the trade of bio-energy between continents. The size of the arrows is not related to the percentage traded, since the small trade volume would make the arrows invisibly small. The trade between continents is only $0.45 \%$ of all bio-energy production if fuel wood is included. Within this small share of bio-energy that is traded, Europe is virtually the only importer, with the largest imports coming from Russia and Eastern Europe. Africa and Asia produce mostly for themselves, as do the Middle East and Oceania at much smaller volumes. South America is an intermediate producer and also exports bioenergy to both Europe and North America.

Fig. 1D shows the intercontinental trade and production of fossil energy (coal, oil and gas). The Middle East is the third largest producer of fossil fuels, after Asia and North America, and on par with Russia and Eastern Europe. However, regarding intercontinental trade the Middle East is by far the largest exporter. The main importer is Asia, followed by Europe, while North America is less dependent on fossil imports.

From the combination of these four maps, we see that the global
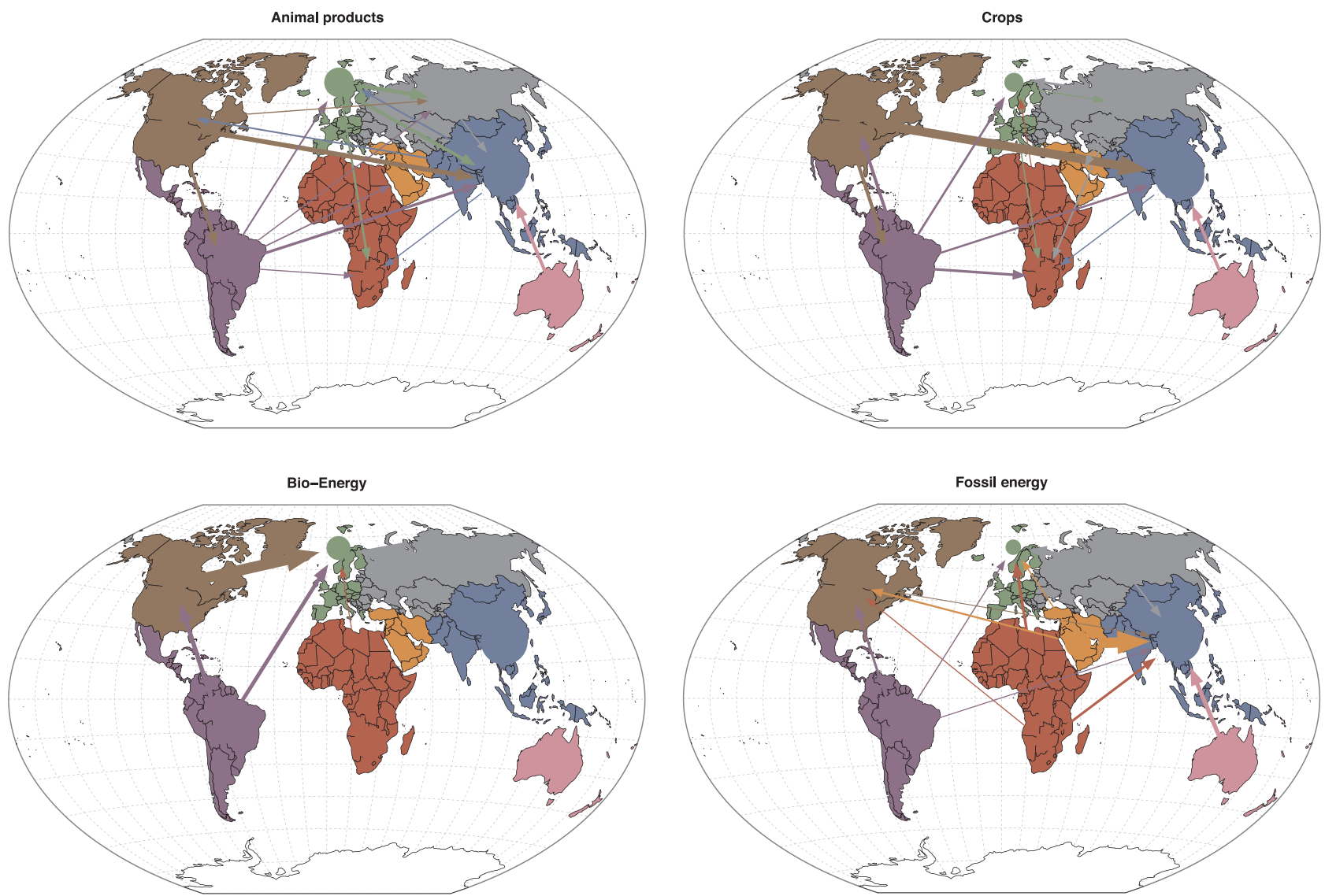

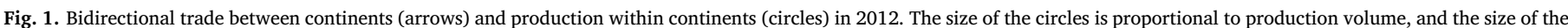

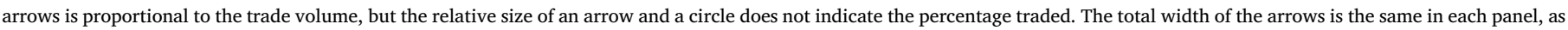
is the total surface area of the circles. Only trade flows larger than $2 \%$ of global trade are shown. 


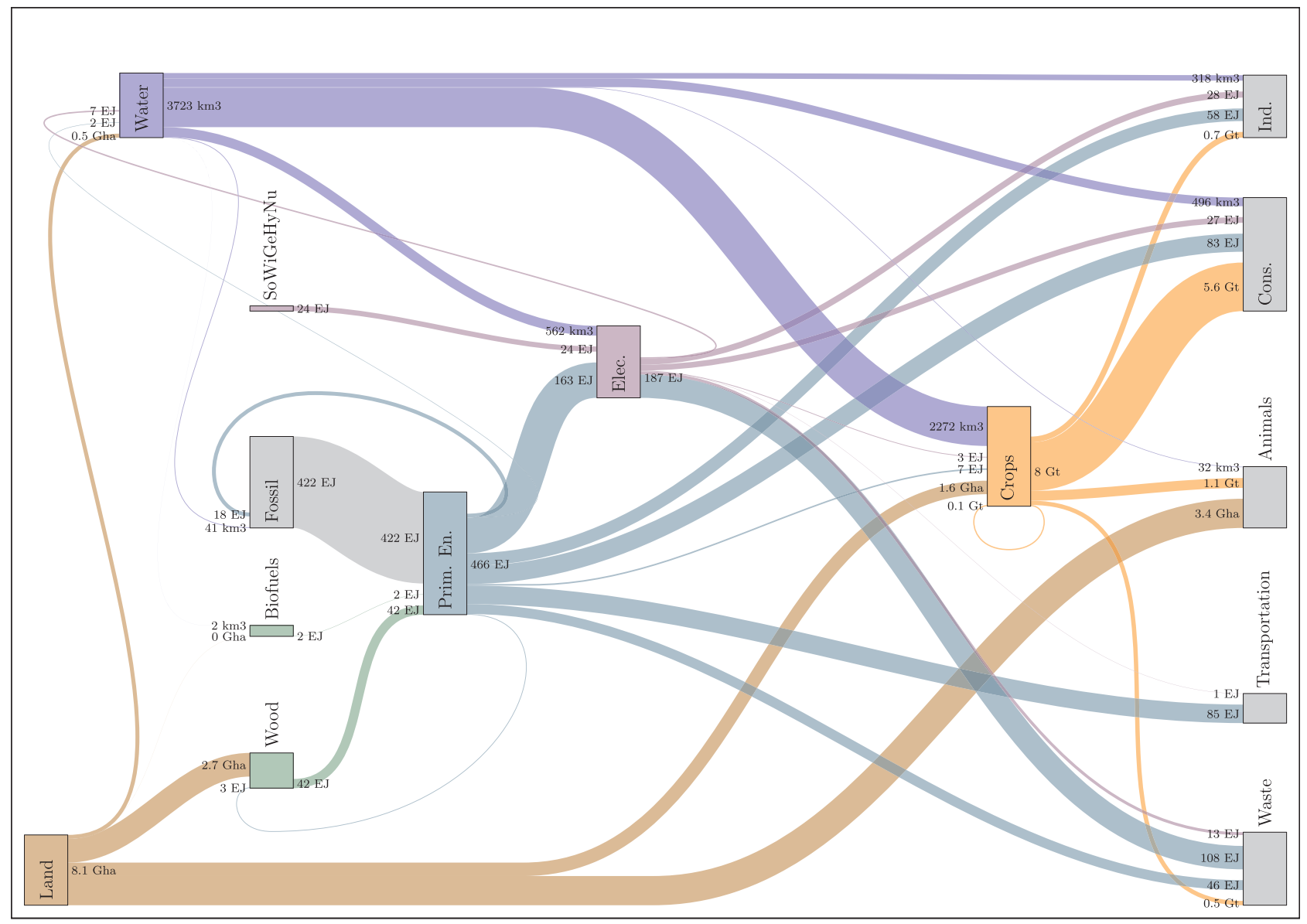

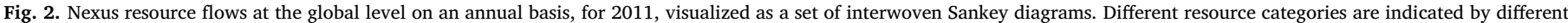

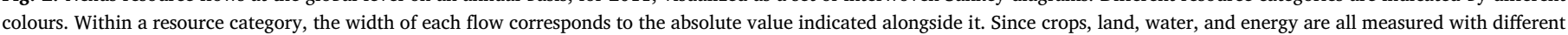

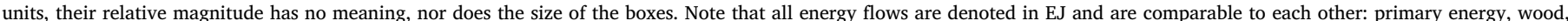
biofuels, fossil fuels, and electricity - SoWiGeHyNu indicates electricity produced by solar, wind, geothermal, hydropower and nuclear technologies.

trade patterns are very different for each resource. Note that the different production, use and flow of resources on each continent also depends on socio-economic factors. For example, Africa is a net food importer (both in terms of crops and animal products) and an energy exporter, which is partly due to the natural resource endowments, but also a result of the current development stage (low domestic energy use and limited infrastructure for trade within the continent). Europe is very different, importing all kinds of nexus resources, but is also one of the largest exporters of animal products, despite having a relatively high population density.

\subsection{Dependencies between water, food, energy and land}

A major reason for viewing demand and supply of basic resources in an integrated nexus, is that some of these resources are used in the production of others. We therefore investigate how water, food and energy depend on each other (Fig. 2), and we include land since it is an important input for both food and bio-energy. Electricity production is also shown, since both primary energy and water are used in the production of electricity. In order to show the relative magnitudes of the various resource flows, we include the main end use categories in the analysis: consumers, industry, transportation and waste. Animal products (meat, milk, etc.) are presented here as an end use category, since these are not used as an input for the production of water, food, energy or land.

The nexus resource flows are shown in Fig. 2, but only include land used directly for human purposes, and only water withdrawal from freshwater sources. The resource categories land, primary energy and water are not homogeneous. For instance, land suitable for grazing or forestry may not be suitable for growing crops, not all primary energy used in power plants is suitable for transportation (e.g. coal), and it may not be possible to divert irrigation water towards electricity generation if these activities take place in different locations or seasons. These heterogeneities are a major reason why nexus interactions need to be examined at a finer spatial, temporal, and commodity resolution. The flows that are small in Fig. 2 can also become important at finer resolutions. However, the global overview in Fig. 2 provides a quantified context for smaller-scale nexus studies. Among the strongest connections are the use of fossil fuels for primary energy, the large land use for animal husbandry, and the large share of crop irrigation in total water use.

Most crops are used for consumption (both directly and as processed food), followed at a distance by animal feed and then industrial use. Note that animal feed makes up a larger proportion when measured in terms of energy. The waste from crops (excluding residues) is only $6 \%$, but this does not include food waste within households, which is included in the 'consumers' end use.

For direct use of primary energy, consumers are the largest end use category (for heating and cooking). Transportation (gasoline and kerosene) uses about the same amount in primary energy equivalent. Energy losses and waste are substantial: $71 \mathrm{EJ}$ of primary energy is wasted and another $121 \mathrm{EJ}$ is lost in the conversion to electricity and during electricity transmission along the grid. Together, this amounts to $39 \%$ of all primary energy. Also note that end-use losses are not shown here, e.g. electric cars convert about $60 \%$ of the electricity from the grid to power at the wheels, compared to about $20 \%$ of the gasoline for 
combustion engines (USDoE, n.d.).

Fig. 2 also highlights how small some of the resource flows are in a global context. Water withdrawal for fossil fuel extraction is almost invisible, as is the component of biofuels in primary energy, and the use of primary energy for producing fuel wood and charcoal. Use of primary energy and electricity for agriculture and for water pumping are also very small.

A key advantage of displaying resource flows in a Sankey diagram as above, is that leverage points and bottle-necks for system change can be identified visually. For example, if the goal is to return more land to its natural state, an obvious starting point is to reduce consumption of animal products. Depending on the type of animal products reduced, this results in direct reduction of demand for pasture land use, as well as indirect reduction of land use via a smaller crop-to-feed flow (which may also save irrigation water as a side effect). As another example, if the goal is to reduce the use of fossil fuels, the diagram shows this is a serious challenge. Replacing all fossil fuels by wood and biofuels seems impossible, simply because of the magnitude of the flows and the consequences for land use (although the forest land use shown here is a very rough estimate and biomass yields can be improved). Since biomass can only partially replace fossil fuels, overall primary energy use would need to decrease as well. For many end uses, primary energy can be replaced by additional electricity from non-fossil sources (SoWiGeHyNu in Fig. 2). This would also reduce the waste flow from electricity, since less primary energy needs to be converted electricity. Indicated by the flow from water to electricity production, there are also consequences for the water system: solar, wind and geothermal technologies clearly save water compared to fossil fuel power plants, while nuclear may use slightly more. The effects of hydropower do not fit neatly into this diagram, because hydropower reservoirs both decrease water supply via evaporation, and increase it by storing water over time (Herath et al., 2011; Zeng et al., 2017).

We further summarize Fig. 2 by calculating percentages and displaying it as a table of direct dependencies between outputs and inputs (Table 3). Electricity usage is back-calculated to primary energy equivalent.

Table 3 shows the direct dependencies between the nexus resources at the global level, with the input columns water, crops, energy and land, and the output rows water, food (crops and animals), energy (fuel wood, biofuels, fossil fuels, and electricity), and various end uses (e.g. industrial and municipal use). The uses are shown as a percentage of the global resource use, to get a common indicator of how strong the dependence relations are.

When examining the dependencies between food, water and energy in Table 3, a few important insights are found. First, water is mainly an input to the rest of the nexus. The inputs for water are energy (2\%) and land $(6 \%)$, and these are relatively small. Secondly, comparatively little energy is used for water (2\%) and food production (3\%), thus energy is mostly an output in terms of nexus relationships and not much of an input. Thirdly, biofuel crop production was still very small $(0.5 \%)$ compared to overall crop production in 2011. Fourthly, water is mainly used for crops (61\%) and comparatively little for energy (16\% in total). Finally, land is similar to water: an input mostly to food (19\% crops, $42 \%$ pasture) and also to energy (roughly $34 \%$ forest).

Through this table of dependencies, a simplified view emerges of the WFE nexus at the global scale. Interesting is that we do not see a highlyinterconnected nexus, but rather a set of dependencies that go mostly in one direction. Most of the water and land in the world is used for food production, while a smaller part of the water and land is used for energy production. Almost all the food and energy is consumed by end users: industries, consumers, transportation, animals and waste. Thus, although bidirectional dependency of nexus resources (i.e. A depends on B while B depends on A) does happen at the global level, the dependencies are much stronger in one direction than the other.

\subsection{Indirect use and resource-saving imports}

Since water, crops and energy are both outputs and inputs in Table 3, there is implicit indirect resource use as well. For example, $8 \%$ of all crops are used in industrial non-food applications, and crops use $61 \%$ of all water withdrawn from rivers and groundwater, thus $0.08 \times 0.61=4.9 \%$ of water withdrawal could be classified as indirect industrial use via crops. Focusing on the large percentages, we find that household consumption of crops (direct and processed) uses roughly $0.69 \times 0.61=42 \%$ of all water withdrawal via crops. Food production from animals uses only $1 \%$ of all water withdrawal directly, but a much

Table 3

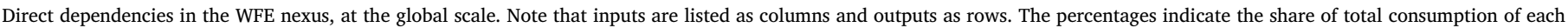
input category, in 2011 .

\begin{tabular}{|c|c|c|c|c|c|c|c|c|}
\hline \multirow{2}{*}{$\begin{array}{l}\text { Inputs: Outputs: } \\
\text { Unit }\end{array}$} & \multicolumn{2}{|c|}{ Water withdrawal } & \multicolumn{2}{|c|}{ Crops use (food and biofuel crops) } & \multicolumn{2}{|c|}{ Energy use ${ }^{\text {a }}$} & \multicolumn{2}{|c|}{ Land use ${ }^{b}$} \\
\hline & & $\mathrm{kg}$ & & $\mathrm{kg}$ & & $\mathrm{J}$ & & $\mathrm{km}^{2}$ \\
\hline for Water & - & - & - & - & $2 \%$ & abstraction, treatment, desalination etc. & $6 \%$ & inland water ${ }^{c}$ \\
\hline for Food (crops) & $61 \%$ & irrigation & $2 \%$ & seed & $3 \%$ & agriculture $^{\mathrm{d}}$ & $19 \%$ & crops \\
\hline (animal) & $1 \%$ & livestock & $14 \%$ & animal feed & - & - & $42 \%$ & pasture \\
\hline \multirow[t]{4}{*}{ for Energy } & $0 \%$ & fuel wood ${ }^{e}$ & - & - & $1 \%$ & fuel wood & $34 \%$ & forest ${ }^{\mathrm{f}}$ \\
\hline & $0.1 \%$ & biofuels & $0.5 \%$ & biofuels & $\sim 0 \%$ & biofuels & $0.1 \%$ & biofuels \\
\hline & $1 \%$ & fossil fuel extraction \& refining & - & - & $4 \%$ & fossil fuel extraction & - & - \\
\hline & $15 \%$ & electricity generation & - & - & $33 \%$ & electricity for end uses ${ }^{g}$ & - & - \\
\hline \multirow[t]{4}{*}{ for End Uses } & $9 \%$ & industrial & $8 \%$ & industry/other & $13 \%$ & industrial $^{\mathrm{g}}$ & - & - \\
\hline & $13 \%$ & municipal & $44 \%$ & direct food ${ }^{\mathrm{h}}$ & $18 \%$ & municipal $^{g}$ & - & - \\
\hline & - & - & $25 \%$ & processed food $^{\mathrm{h}}$ & $7 \%$ & feedstock ${ }^{g}$ & - & - \\
\hline & - & - & $6 \%$ & waste in storage/transport & $19 \%$ & transport $^{g}$ & - & - \\
\hline Total & $100 \%$ & & $100 \%$ & & $100 \%$ & & $100 \%$ & \\
\hline
\end{tabular}

The rows for End Uses are displayed in italic font, because these are not an integral part of the resource nexus.

${ }^{\text {a }}$ All energy forms, in primary energy equivalents. Electricity is not only an output, but also an input in this table, since for instance electricity-powered water pumps are included in the energy-for-water number. See also note 'below.

${ }^{\mathrm{b}}$ Excludes minimally used land such as mountains, deserts and standing forests.

${ }^{\mathrm{c}}$ Land surface area covered by lakes, thus excluding the fact that land and vegetation act as a buffer between precipitation events and stream flow.

d Excluding food processing industry and transportation of food, which are included in the 'Industrial' and 'Transport' end uses, respectively.

e We assume fuel wood is not irrigated.

${ }^{\mathrm{f}}$ Roughly estimated as the area where forest is re-growing after human influence.

${ }^{\mathrm{g}}$ Since "electricity for end uses" is listed separately, the energy for each specific end use (industrial/municipal/feedstock/transport) includes only non-electric forms of energy consumption, whether primary (e.g. fuel wood or natural gas) or secondary (e.g. gasoline), but all in primary energy equivalent numbers.

${ }^{\mathrm{h}}$ Includes food waste at the household level. 
larger amount $(0.14 \times 0.61=9 \%)$ via feed crops using irrigation water. On the other hand, animal food products require $42 \%$ of all human land use directly as pasture, but only $0.14 \times 0.19=2.7 \%$ of land via feed crops.

Related to indirect use are virtual trade and resource-saving imports. These are only significant when large volumes of resource A are used in producing resource B (Table 3), and simultaneously significant amounts of resource B are traded internationally (Table 2). This is the case for water via crops, land via crops, land via animals, and to some extent crops via animals. For these resources, trade in resource B could alleviate the local scarcity of resource A (by virtual supply from locations where $\mathrm{A}$ is abundant). For example, regions where food production (B) is limited by local water scarcity (A) are likely to import food from water-rich locations. In these cases, the continental and global scales become relevant when examining resource A (water), even if this resource is difficult to trade directly. The implications of such virtual trade can be multiple: 1) alleviating local scarcity (as in the example), but also 2) areas becoming increasingly dependent on trade and 3) in some cases, trade flows that could harm the exporting region (e.g. exports of agricultural products from water scarce regions).

Here, we focus on the potential to alleviate local scarcity. We calculate resource-saving imports, which is the component of virtual trade that is relevant for importing countries with resource scarcities. Besides water saved by importing crops, we also estimate water saved by importing animal products, and water saved by saving feed crops by importing animal products (Fig. 3). Fig. 4 shows the estimated land area saved via the same three mechanisms.

Fig. 3 compares the water withdrawal saved by imports with the actual domestic water withdrawal (as modelled in LPJmL). The global total water withdrawal saved by importing crops and animal products is about a factor 10 smaller than domestic water use. However, at the regional level, the resource-saving imports can be significant. The water savings are almost as large as water use in the Middle East, roughly half in Mexico, Northern Africa and Korea, around 30\% in Rest of Central
America and Eastern Africa, and around 20\% in Japan and Rest of Southern Asia. For the Middle East, Northern Africa and Mexico, these water-saving imports are probably a response to local water scarcity (Bijl et al., 2017a, 2017bunder review.). For Korea and Japan, water scarcity is much less severe, and the food imports could be motivated by the high population density instead, i.e. a lack of land rather than water.

When comparing the three mechanisms by which food imports can save water, it is clear that water saved directly by importing animal products is completely insignificant (although this is partly because we examine water use in terms of withdrawal rather than consumption). However, animal imports do save significant water volumes indirectly by avoiding domestic cultivation of feed crops: about $60 \mathrm{~km}^{3} /$ year globally, compared to almost $300 \mathrm{~km}^{3} /$ year saved by direct crop imports.

Fig. 4 compares the land area saved by food imports with the land area used for agricultural purposes. For Korea and Japan, more land is saved by importing crops and animals than is used domestically. For all other regions, land savings play a much smaller role, although it is still roughly half as large as domestic land use in Rest of Central America, Northern Africa and the Middle East. At the global level, land savings are only $12 \%$ as large as land use.

Looking at the three different land saving mechanisms, direct savings via imported animal products are the largest (356 Mha), followed by direct savings via crop imports ( $163 \mathrm{Mha}$ ), with indirect savings via avoided feed crops coming last (60 Mha). This reflects the high overall land intensity of animal products compared to crops (two-thirds of global agricultural land is grassland versus one-third cropland).

\section{Discussion}

In this paper, we have analysed the physical characteristics of nexus resources related to spatial scales (Section 3.1), the patterns of production and trade at the continental scale (Section 3.2), the direct
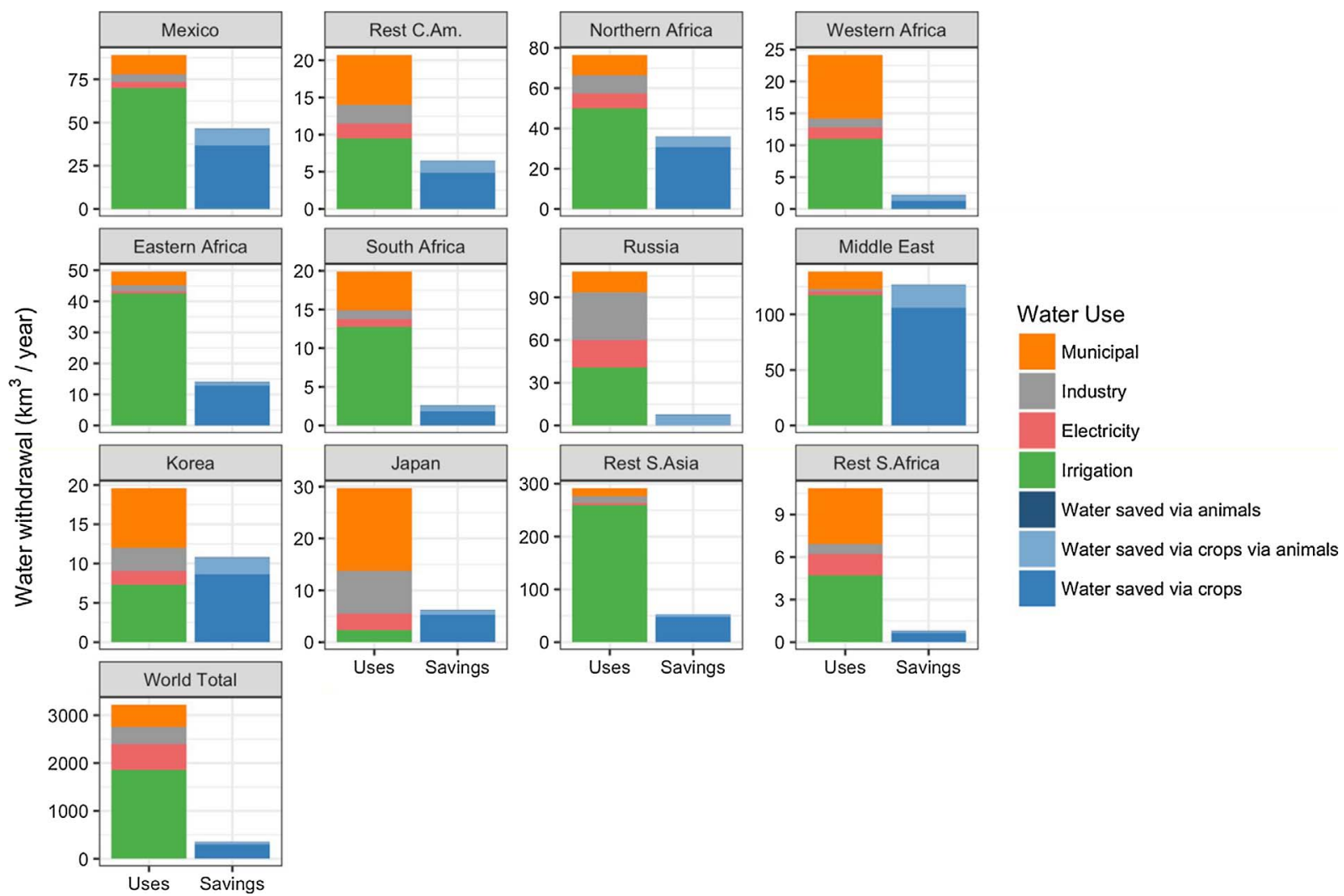

Fig. 3. Water use (left) and water saved by importing crops and animal products (right), in 2010 . Only those regions are shown, for which total water saved $>0.06 \times$ water used. 

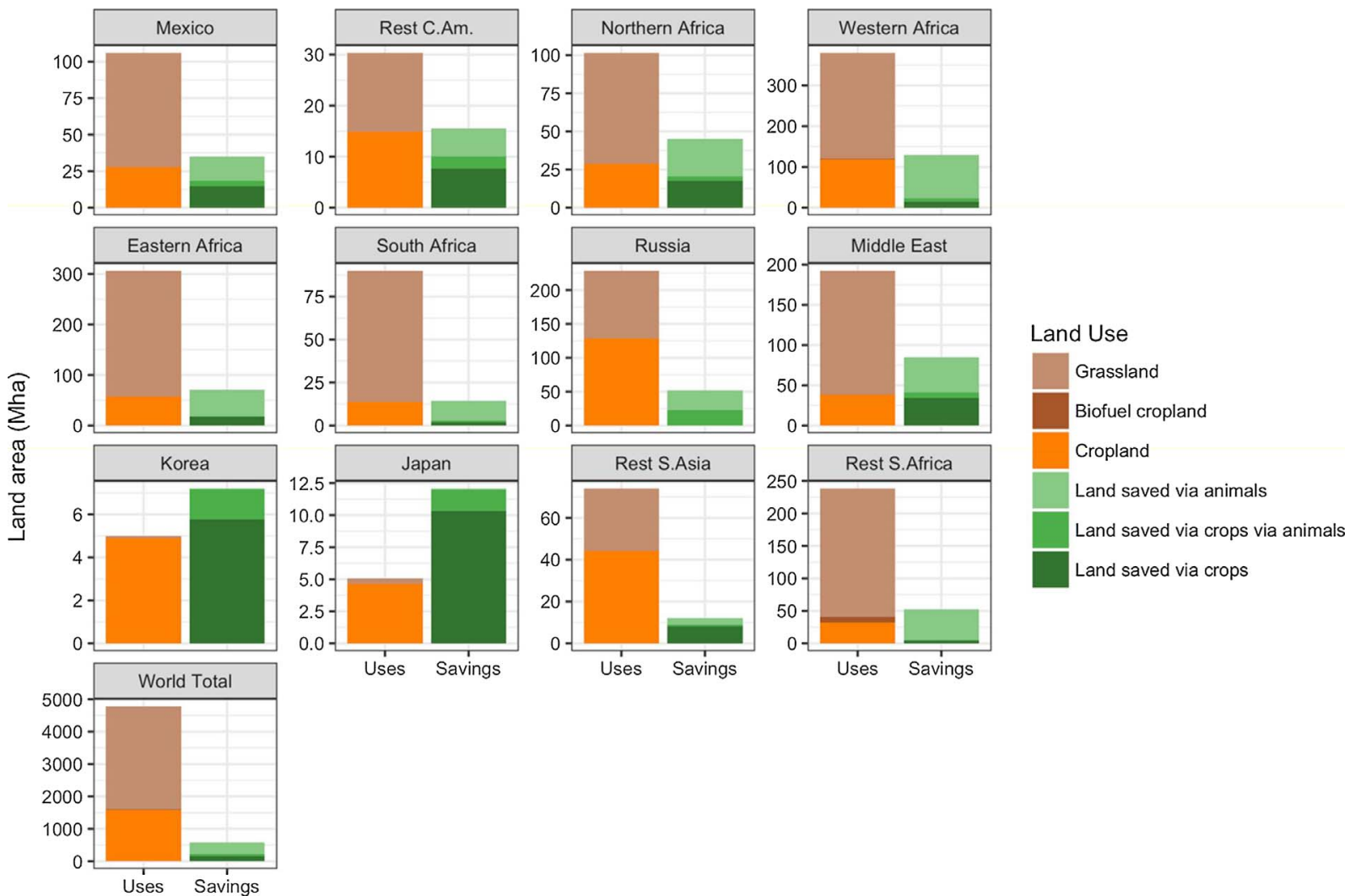

Fig. 4. Land use (left) and land saved by importing crops and animal products (right), in 2010 . Only those regions are shown, for which total land saved $>0.1 \times$ land used.

dependencies between nexus resources at the global scale (Section 3.3), and the role of resource-saving imports in the nexus (Section 3.4). Some of these factors may change considerably in the future as a result of socio-economic trends and climate change. In the Supplementary information, we qualitatively discuss potential future changes and how these may impact the relevant spatial scales for each nexus resource.

Our analysis has focused at the global and continental levels, but we have not yet systematically examined data at smaller spatial scales. We also glossed over the heterogeneities within the resource categories, especially regarding water, land, crops, animal products and bio-energy. Specific types or qualities of a resource are sometimes required for specific applications (e.g. water for cooling power plants must be quite clean and not too warm, and every crop requires different soil characteristics). Also note that the physical indicators and other values calculated in this paper can be very different for smaller sub-categories.

We have calculated indirect resource uses based on direct dependencies at the global level (Table 3), but these are of course very rough estimates. For example, the water used by crops used for industry varies substantially based on the crop types used by industry and the locations where these are grown. Life Cycle Analysis (LCA) is a more suitable tool for investigating indirect resource use in detail. However, these are often applied to specific products or companies, whereas our global calculations can quickly indicate whether any indirect dependencies might be relevant at the global scale.

The resource-saving imports presented in Section 3.4 are also rough estimates, among others because the domestic intensities (e.g. water needed per ton of crops produced) are based on current domestic resource use. The domestic resource intensity in the hypothetical case without imports (thus with more domestic production) can be higher due to diminishing returns or lower due to economies of scale.

There are several opportunities for further research. Our analysis suggests that the continental and global context cannot be ignored when analysing nexus issues at local, watershed or national levels. Therefore, it would be particularly interesting to build a computational model of resource nexus trade-offs at the local scale (e.g. $\left.0.5 \times 0.5^{\circ}\right)$, with global coverage. Some integrated assessment models such as IMAGE compute water use and food production at this level, but are not geared to analysing nexus trade-offs under locally varying socio-technological regimes (Foran, 2015). To implement such a model, the geographic locations of future demand and supply of the resources would be needed. For demand, specific locations of population and income from household surveys could be coupled with income-driven demand models (Bijl et al., 2017a, 2017b, 2016). However, this is still a major challenge because the uncertainty increases dramatically with finer resolutions and longer time horizons (e.g. where to expect further urbanization). An even greater challenge would be to make global maps of the laws, regulations and attitudes towards basic resources at each location, and of the locally viable technologies and how these may spread in the future.

\section{Conclusion}

The resources in the WFE nexus are very different in terms of absolute magnitude of production, as well as in the extent to which they are traded. Global water withdrawal is three orders of magnitude larger than food and energy flows in terms of mass. In turn, total energy flows are a factor 1.6 larger than food in terms of mass, and a factor 9 larger in terms of energy content. Global trade as percentage of production also differs considerably. It is highest for oil (51\%), gas (29\%) and coal $(21 \%)$, followed by crops and animal products (both $7 \%)$, whereas bio-energy $(1 \%)$ and water $(\sim 0 \%)$ are hardly traded at all. The average trade distance follows a similar pattern.

The spatial scales involved in physical trade are related to physical characteristics of each resource. We hypothesized that the spatial scales could be related to the physical characteristics of the resources. Indeed, we found that the following factors, taken together, can explain some of the differences in trade extent: high priced, high density, geographically concentrated resources are traded more and 
over longer distances.

Nexus resources depend on each other for their production, but most of these direct dependencies are very small at the global

level. Interdependence of two resources is not really an issue at the global level, since the direct dependencies go mostly in one direction: food depends on water and land, and to a smaller extent energy also depends on water and land. However, bidirectional dependencies between nexus resources are more likely to be found at smaller spatial scales.

The analysis shows that the global and continental scales are important for nexus problems, providing solutions beyond the local or national scales. The global and continental scales are important, since physical trade and resource-saving imports can alleviate resource scarcities and unwanted dependencies at the smaller spatial scales. The estimated water withdrawal saved by importing crops and animal products is significant for specific regions: savings are roughly as large as water use in the Middle East, and roughly half as large in Mexico, Northern Africa and Korea. Globally, crop imports save roughly $300 \mathrm{~km}^{3} /$ year, while imported animal products save an additional $60 \mathrm{~km}^{3} /$ year by avoiding domestic cultivation of feed crops. The same imports also save land: 356 Mha directly via imported animal products, 163 Mha via crop imports, and 60 Mha indirectly via avoided feed crops.

\section{Acknowledgments}

The research leading to these results has received funding from the Rabobank Foundation.

\section{Appendix A. Supplementary data}

Supplementary data associated with this article can be found, in the online version, at doi:10.1016/j.gloenvcha.2017.11.005.

\section{References}

BEA, 2016. USA GDP Deflator.

Bailis, R., Rujanavech, C., Dwivedi, P., de Oliveira Vilela, A., Chang, H., de Miranda, R.C., 2013. Innovation in charcoal production: a comparative life-cycle assessment of two kiln technologies in Brazil. Energy Sustain. Dev. 17, 189-200. http://dx.doi.org/10. 1016/j.esd.2012.10.008.

Bazilian, M., Rogner, H., Howells, M., Hermann, S., Arent, D., Gielen, D., Steduto, P., Mueller, A., Komor, P., Tol, R.S.J., Yumkella, K.K., 2011. Considering the energy, water and food nexus: towards an integrated modelling approach. Energy Policy 39, 7896-7906. http://dx.doi.org/10.1016/j.enpol.2011.09.039.

Biggs, E.M., Bruce, E., Boruff, B., Duncan, J.M.A., Horsley, J., Pauli, N., McNeill, K., Neef, A., Van Ogtrop, F., Curnow, J., Haworth, B., Duce, S., Imanari, Y., 2015. Sustainable development and the water-energy-food nexus: a perspective on livelihoods. Environ. Sci. Policy 54, 389-397. http://dx.doi.org/10.1016/j.envsci.2015.08.002.

Bijl, D.L., Bogaart, P.W., Kram, T., de Vries, B.J.M., van Vuuren, D.P., 2016. Long-term water demand for electricity, industry and households. Environ. Sci. Policy 55, 75-86. http://dx.doi.org/10.1016/j.envsci.2015.09.005.

Bijl, D.L., Biemans, H., Bogaart, P.W., Dekker, S.C., Doelman, J., Stehfest, E., Van Vuuren, D.P., 2017a. Inter-sectoral water allocation in the water-food-energy nexus. Submitt. Water Resour. Res under review.

Bijl, D.L., Bogaart, P.W., Dekker, S.C., Stehfest, E., de Vries, B.J.M., van Vuuren, D.P., 2017b. A physically-based model of long-term food demand. Glob. Environ. Change 45, 47-62. http://dx.doi.org/10.1016/j.gloenvcha.2017.04.003.

Bizikova, L., Roy, D., Swanson, D., Venema, H.D., McCandless, M., 2013. The waterenergy-food security nexus: towards a practical planning and decision-support framework for landscape investment and risk management. International Institute for Sustainable Development.

Bondeau, A., Smith, P.C., Zaehle, S., Schaphoff, S., Lucht, W., Cramer, W., Gerten, D., Lotze-Campen, H., MüLler, C., Reichstein, M., Smith, B., 2007. Modelling the role of agriculture for the 20th century global terrestrial carbon balance. Glob. Change Biol. 13, 679-706. http://dx.doi.org/10.1111/j.1365-2486.2006.01305.x.

Bos, M.G., Wolters, W., 1990. Water charges and irrigation efficiencies. Irrig. Drain. Syst. 4, 267-278.

Chapagain, A.K., Hoekstra, A.Y., Savenije, H.H.G., 2006. Water saving through international trade of agricultural products. Hydrol. Earth Syst. Sci. Discuss. 10, 455-468.

Comtrade, 2016. UN Comtrade Database [WWW Document]. URL http://comtrade.un. $\mathrm{org} / \mathrm{db} /$ (Accessed 8 September 2016).

FAOSTAT, 2014. Food Balance Sheets [WWW Document]. URL http://faostat3.fao.org/ home/index.html (Accessed 30 July 2014).

FAOSTAT, 2016. FAO Statistical Databases [WWW Document]. URL http://faostat3.fao. org/home/index.html (Accessed 3 Feburary 2016).

Finley, J.W., Seiber, J.N., 2014. The nexus of food, energy, and water. J. Agric. Food Chem. 62, 6255-6262. http://dx.doi.org/10.1021/jf501496r.

Foran, T., 2015. Node and regime: interdisciplinary analysis of water-energy-food nexus in the Mekong region. Water Altern. 8.

Garcia, D.J., You, F., 2016. The water-energy-food nexus and process systems engineering: a new focus. Comput. Chem. Eng. 91, 49-67. http://dx.doi.org/10.1016/j. compchemeng.2016.03.003.

Hall, C.A.S., Lambert, J.G., Balogh, S.B., 2014. EROI of different fuels and the implications for society. Energy Policy 64, 141-152. http://dx.doi.org/10.1016/j.enpol. 2013.05.049.

Hapman, 2016. Bulk Material Density Guide [WWW Document]. URL http://www. hapman.com/resources/bulk-material-density-guide (Accessed 19 October 2016).

Hejazi, M.I., Voisin, N., Liu, L., Bramer, L.M., Fortin, D.C., Hathaway, J.E., Huang, M., Kyle, P., Leung, L.R., Li, H.-Y., Liu, Y., Patel, P.L., Pulsipher, T.C., Rice, J.S., Tesfa, T.K., Vernon, C.R., Zhou, Y., 2015. 21 st century United States emissions mitigation could increase water stress more than the climate change it is mitigating. Proc. Natl. Acad. Sci. 112, 10635-10640. http://dx.doi.org/10.1073/pnas.1421675112.

Hellegers, P., Zilberman, D., Steduto, P., McCornick, P., 2008. Interactions between water, energy, food and environment: evolving perspectives and policy issues. Water Policy 10, 1. http://dx.doi.org/10.2166/wp.2008.048.

Herath, I., Deurer, M., Horne, D., Singh, R., Clothier, B., 2011. The water footprint of hydroelectricity: a methodological comparison from a case study in New Zealand. J. Clean. Prod. 19, 1582-1589. http://dx.doi.org/10.1016/j.jclepro.2011.05.007.

Hoekstra, A.Y., Hung, P.Q., 2002. Virtual water trade Quantif. Virtual Water Flows Nations Relat. Int. Crop Trade. Value Water Res. Rep. Ser. 11, 166.

IEA, 2016a. IEA Headline Energy Data.

IEA, 2016b. World Energy Outlook 2016.

Mayer, T., Zignago, S., 2011. Notes on CEPII's Distances Measures: The GeoDist Database.Notes on CEPII's Distances Measures: The GeoDist Database.

Pandur, Z., Šušnjar, M., Zorić, M., Nevečerel, H., Horvat, D., 2015. Energy return on investment (EROI) of different wood products. In: Zlatic, M. (Ed.), Precious Forests Precious Earth. InTech.

Ringler, C., Bhaduri, A., Lawford, R., 2013. The nexus across water, energy, land and food (WELF): potential for improved resource use efficiency? Curr. Opin. Environ. Sustain. 5, 617-624. http://dx.doi.org/10.1016/j.cosust.2013.11.002.

Ringler, C., Willenbockel, D., Perez, N., Rosegrant, M., Zhu, T., Matthews, N., 2016. Global linkages among energy, food and water: an economic assessment. J. Environ. Stud. Sci. 6, 161-171. http://dx.doi.org/10.1007/s13412-016-0386-5.

SImetric, 2016. Specific Gravity of Liquids [WWW Document]. URL http://www.simetric. co.uk/si_liquids.htm (Accessed 19 October 2016).

Schornagel, J., Niele, F., Worrell, E., Böggemann, M., 2012. Water accounting for (agro) industrial operations and its application to energy pathways. Resour. Conserv. Recycl. 61, 1-15. http://dx.doi.org/10.1016/j.resconrec.2011.12.011.

Stehfest, E., van Vuuren, D.P., Kram, T., Bouwman, L., Alkemade, R., Bakkenes, M., Biemans, H., Bouwman, A., den Elzen, M.G.J., Janse, J., Lucas, P., van Minnen, J., Müller, C., Prins, A., 2014. Integrated Assessment of Global Environmental Change with IMAGE 3.0. Model Description and Policy Applications. PBL Netherlands Environmental Assessment Agency, The Hague.

USDA,, 2016. National Nutrient Database for Standard Reference Release 28.

USDoE, 2013. Liquefied Natural Gas: Understanding the Basic Facts.

USDoE, 2017. USDoE, n.d. All-Electric Vehicles [WWW Document]. URL http://www. fueleconomy.gov/feg/evtech.shtml (Accessed 29 March 2017).

World Economic Forum,, 2011a. Water Security: The Water-Energy-Food-Climate Nexus Island Press, Washington, DC.

World Economic Forum, 2011b. Global Risks 2011: An Initiative of the Risk Response Network. World Economic Forum, Geneva.

Zeng, R., Cai, X., Ringler, C., Zhu, T., 2017. Hydropower versus irrigation-an analysis of global patterns. Environ. Res. Lett. 12, 34006. http://dx.doi.org/10.1088/17489326/aa5f3f.

Zhou, Y., Tol, R.S.J., 2005. Evaluating the costs of desalination and water transport: costs of desalination and water transport. Water Resour. Res. 41http://dx.doi.org/10. 1029/2004WR003749. n/a-n/. 